\title{
Enhanced cardiac fatty acid utilization induced by high dietary fat: a potential regulatory role for mitochondrial aconitase
}

\author{
Jolyn Fernandes ${ }^{1,2^{*}}$, Luke I Szweda ${ }^{1,2,3,4}$, Michael Kinter ${ }^{1,3}$ \\ From Metabolism, diet and disease \\ Washington, DC, USA. 29-31 May 2012
}

\section{Background}

Obesity is an independent risk factor for cardiovascular disease and Type 2 diabetes, a condition that enhances the risk for various cardiomyopathies. Obesity is known to induce a state of metabolic inflexibility within the heart characterized by increased mitochondrial reliance on fatty acids for energy production. While the molecular mechanisms are not fully clarified, these changes in metabolism are thought to contribute to degeneration of cardiovascular function. The focus of my research is to investigate regulatory mechanisms that control dietinduced changes in fatty acid utilization ( $\beta$-oxidation) by cardiac mitochondria.

\section{Materials and methods}

In the current study, we used quantitative proteomics, mitochondrial respiratory analysis, and enzymology to investigate factors that contribute to diet-induced changes in fatty acid utilization by cardiac mitochondria ( $\beta$-oxidation). We employed C57B/6J mice fed a high fat diet ( $60 \% \mathrm{kcal}$ from fat) as a model of obesity with mice fed low a fat diet (10\% kcal from fat) serving as controls.

\section{Results}

Whole pathway analysis by mass spectrometry revealed elevated expression of $\beta$-oxidation enzymes with no change in Krebs cycle enzymes within 2 wk on the high fat diet up to $\leq 60 \mathrm{wk}$. These observations indicate a mismatch between $\beta$-oxidation and the Krebs cycle that is responsible for the consumption of $\beta$-oxidation product, acetyl CoA. This could lead to the buildup of cardiotoxic fatty acid derived intermediates. Subsequent, enzymatic

${ }^{1}$ Free Radical Biology and Aging Program, Oklahoma Medical Research Foundation, Oklahoma City, OK 73104, USA

Full list of author information is available at the end of the article

analysis revealed that citrate synthase, isocitrate dehydrogenase, and $\alpha$-ketoglutarate dehydrogenase, the key regulatory enzymes of the Krebs cycle, exhibited no change in activity. However, mitochondrial aconitase activity was increased approximately $60 \%$ with no change in expression suggesting a role for post translational modifications. Increased aconitase specific activity was observed within $2 \mathrm{wk}$ on the high-fat diet and persisted with extended dietary durations ( $\leq 60 \mathrm{wk})$.

\section{Conclusions}

The increase in cardiac mitochondrial aconitase activity in response to high dietary fat highlights a potential novel regulatory role for the enzyme in $\beta$-oxidation. In the cytosol, citrate can be converted to malonyl CoA, a potent inhibitor of $\beta$-oxidation. Citrate is also an allosteric activator of acetyl CoA carboxylase, the enzyme that produces malonyl CoA. Since aconitase converts citrate to isocitrate, an increase in aconitase activity within the mitochondria has the potential to reduce citrate efflux and thus promote $\beta$-oxidation. These events could contribute to dietary-induced metabolic inflexibility.

\section{Funding}

NIH.

\section{Author details}

${ }^{1}$ Free Radical Biology and Aging Program, Oklahoma Medical Research Foundation, Oklahoma City, OK 73104, USA. ²Department of Biochemistry and Molecular Biology, University of Oklahoma Health Science Center, Oklahoma City, OK 73104, USA. ${ }^{3}$ Department of Geriatric Medicine, Reynolds Oklahoma Center on Aging, University of Oklahoma Health Science Center, Oklahoma City, OK 73104, USA. ${ }^{4}$ Department of Medicine, Section of Endocrinology and Diabetes, University of Oklahoma Health Science Center, Oklahoma City, OK73104, USA. 
doi:10.1186/1753-6561-6-S3-P15

Cite this article as: Fernandes et al:: Enhanced cardiac fatty acid utilization induced by high dietary fat: a potential regulatory role for mitochondrial aconitase. BMC Proceedings 2012 6(Suppl 3):P15.

Submit your next manuscript to BioMed Central and take full advantage of:

- Convenient online submission

- Thorough peer review

- No space constraints or color figure charges

- Immediate publication on acceptance

- Inclusion in PubMed, CAS, Scopus and Google Scholar

- Research which is freely available for redistribution

Submit your manuscript at www.biomedcentral.com/submit
C Biomed Central 